Physical Geography; Cartography; Geographic Information Systems \& Spatial Planing

\title{
AN APPROACH OF GIS BASED ASSESSMENT OF SOIL EROSION RATE ON COUNTRY LEVEL IN THE CASE OF MACEDONIA
}

DOI: http://dx.doi.org/10.18509/GBP.2015.13

UDC: 007:004]:[528.8:551.311 (497.7)

\author{
Assoc. Prof. Dr. Ivica Milevski \\ Faculty of Sciences, Ss. Cyril and Methodius University, Republic of Macedonia
}

\begin{abstract}
One of the major environmental problems in the Republic of Macedonia is accelerated soil erosion. Steep slopes of the terrain combined with soft rocks (schists on the mountains; sands and sandstones in depressions), erodible soils, semi-arid continental climate and sparse vegetation cover, give high potential for soil erosion. For that reasons, different approaches and methods are used for assessment of soil erosion intensity in the country. Aside of field analyses and hydrological measurements, estimation of average soil erosion potential and sediment yield is generally achieved with Erosion Potential Model (EPM) of Gavrilovic [5] as one of the most frequently used in the region. However, unlike the traditional approach with high subjectivity, in latest decade GIS approach of EPM is introduced, with most of the model parameters derived from digital elevation model and satellite imagery. In this paper, one such approach for the entire country is presented, after numerous evaluations of smaller catchments. The results in general are similar with Soil Erosion Map of the Republic of Macedonia, but there are some significant local differences.
\end{abstract}

Keywords: GIS, soil erosion, natural hazards, EPM

\section{INTRODUCTION}

Soil erosion by water is a widespread problem throughout Europe. Erosion rate is very sensitive to both climate and land use, therefore southern Europe and the Mediterranean region is particularly prone to erosion because it is subject to long dry periods followed by heavy bursts of erosive rain, falling on steep slopes with fragile soils [6]. In this regard, Republic of Macedonia is highly exposed and devastated by soil erosion. One of the key factors for that is uncontrolled deforestation in the past as well as inappropriate land use and high human impact on the landscape. Some of the most devastating effects are large areas with excess erosion, flash floods, landscape degradation and significant damages to the local and national economy. Because of that, assessment of soil erosion intensity and identification of endangered areas is very significant for better prevention and protection of landscape and population [3]. For assessment of soil erosion risk, generally, three types of approaches exist in Europe [4]: qualitative approach, quantitative approach, and model approach, all of which vary in their characteristics and applicability. In last two decades, already developed models and approaches are improved through the use of geospatial databases developed using GIS technology. In practical applications, advantage usually is given to the most known, well-evaluated and tested empirical models USLE, PESERA, KINEROS, WEP, WEPP etc. However, there are few locally used, not so widely known models which were shown as pretty accurate and easy to use [5]. One of these is Erosion Potential Model (EPM) of Gavrilović (1972) which has been successfully applied and tested in various regions and entire countries on the Balkan Peninsula and wider, showing 
very good results [5]. For that reasons, there was several attempts to adopt EPM to GISbased approach [8],[6], and in this paper is represented last update which is tested in details.

\section{METHODOLOGY}

In Macedonia, as well as in other countries in the region, estimation of average soil erosion potential and sediment yield is generally achieved with Erosion Potential Model (EPM) of Gavrilović (1972). The equation is $\mathrm{W}_{\mathrm{y}}=\mathrm{T} \cdot \mathrm{H} \cdot 3.14 \cdot \mathrm{sqrtZ}^{3} \cdot \mathrm{f}$, where: $\mathrm{W}$ is average annual soil erosion in $\mathrm{m}^{3} ; \mathrm{T}$ is temperature coefficient in form: $\mathrm{T}=(0.1 \cdot \mathrm{t}+$ $0.1)^{0.5}$, where $\mathrm{t}$ is mean annual air temperature; $\mathrm{H}$ is mean annual precipitation in $\mathrm{mm} ; \mathrm{Z}$ is erosion coefficient ranging from 0.1 to 1.5 and over; and $\mathrm{f}$ is study area in $\mathrm{km}^{2}$. Among these factors, coefficient $\mathrm{Z}$ has the highest importance combining: soil erodibility (Y), land cover index $(\mathrm{Xa})$, index of visible erosion processes $(\varphi)$, and mean catchment slope $(\mathrm{J})$ in relation: $\mathrm{Z}=\mathrm{Y} \cdot \mathrm{Xa} \cdot\left(\varphi+\mathrm{sqrtJ}^{0.5}\right)$. Values of $\mathrm{Z}$ usually ranged between 0 (no erosion) and 1.5 (excess erosion). Based on this traditional catchment oriented approach, erosion map of the Republic of Macedonia is made [2]. However, determination of some significant factors in the model as coefficient $\varphi$ (visible erosion processes) and $X^{*}$ a (land cover index) were subjective (expert-related) in nature since of visual estimation. Because of that, in GIS approach of the model most of the parameters are derived from digital elevation model (DEM), satellite imagery and other digital thematic maps [9]. Thus, for the GIS-based EPM assessment of the Republic of Macedonia, set of very detailed digital models and grids with $20 \mathrm{~m}$ resolution are prepared, evaluated and used.

For erodibility coefficient Y, digitalized and rasterized lithology map is prepared with corresponding values for the rock erodibility proposed by Gavrilović [5]. In general, values range from 0.1 (very solid rocks like marble, limestone quartzite etc.) to 2.0 (very soft rocks like sand, sandstone, tuff etc.). However, because it is very difficult to estimate exact erodibility, value fitting is made with double square rooting in form: $\mathrm{Y}=$ $\operatorname{sqrt}\left(\operatorname{sqrt}\left(\mathrm{Y}_{1}\right)\right)$ (Fig. 1).

Land cover index $\mathrm{X}^{*} \mathrm{a}$ is prepared from CORINE Land cover model (CLC2006) with values proposed by original model ranging from 0.1 (dense forests) to 1.0 (bare soils).

For the value of coefficient $\varphi$ of visible erosion processes, instead of very subjective estimation in traditional model, Landsat ETM+ band 3 (b3-red) or Landsat 8 (b4-red) is used in such way that grayscale values $(0-255)$ are divided by 255 . That is because this channel has 255 tones of gray where low values correspond to areas without visible erosion processes, and values near 255 usually correspond to areas with excess erosion (Fig. 1). However, high values may also represent light anthropogenic objects, uncovered soils and rocks, deposition sites etc. For that reason, correction with slope gradient (a) in form: $\varphi=\left((b 3 / 255)^{*} \log (a+1)\right)$ is made, resulting in much more accurate values for coefficient $\varphi[11]$.

Slope factor $\mathrm{J}$ is calculated from high quality $20 \mathrm{~m}$ DEM as a raster layer for slope angle in radians $(\mathrm{a}=\mathrm{a} / 57.3)$. Finally, GIS-calibrated coefficient $\mathrm{Z}$ is calculated according to the equation:

$$
\mathrm{Z}=\operatorname{sqrt}(\operatorname{sqrt}(\mathrm{Y}))^{*} \varphi^{*}\left(\left(\mathrm{X}^{*} \mathrm{a}+\varphi\right) * \log (\mathrm{a}+1)+\operatorname{sqrt}(\mathrm{a} / 57.3)\right)
$$

Climate parameters in the model e.g. temperature coefficient $(\mathrm{T})$ and mean annual sum of precipitations $(\mathrm{H})$ are prepared with combination of real data from meteorological stations in the Republic of Macedonia and corresponding vertical gradients. Firstly, position and mean temperature/precipitation values (1961-1990) for 30 meteorological 
stations across the country are inserted on the map as a vector points with attributes. The next step was gridding (rasterize) of these values using Modified Quadratic Shepard module in SAGA GIS v2. The produced grids of temperatures and precipitations are checked well for consistency and accuracy after which altitude regression scatterplots in regard to the $20 \mathrm{~m}$ DEM are calculated. With these regressions, raster grids of mean temperature and precipitation based on vertical gradients were generated. Final models are produced with averaging of grids of interpolated real data and vertical gradient grids [11].
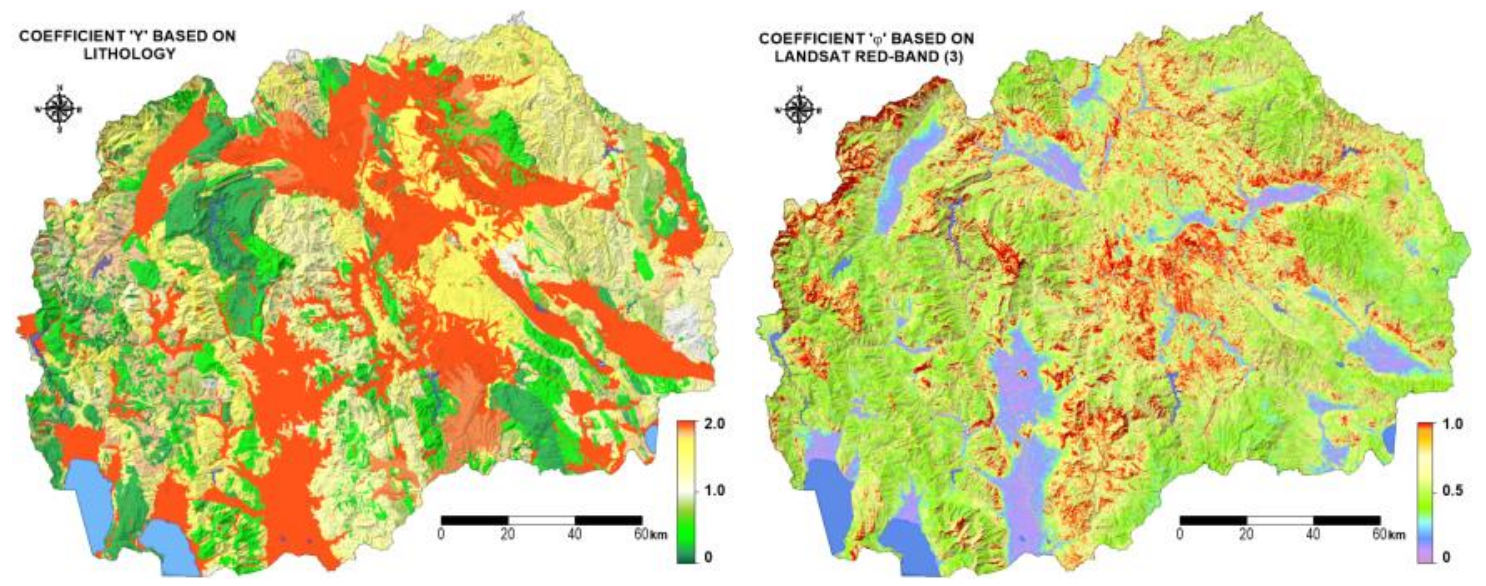

Figure 1. Digital models of erodibility coefficient "Y" and coefficient " $\varphi$ ".

Having available temperature and precipitation grids, as well as the erosion coefficient grid $(\mathrm{Z})$, final mean annual erosion loss $\left(\mathrm{W}_{\mathrm{y}}\right)$ for the entire country is calculated. This GIS-based methodology is previously tested with researches in different regions and catchments in the Republic of Macedonia showing good results when comparing with measured and observed data [10]. Also, because of exactly defined approach, real comparisons of different areas or different periods are possible, without the issue of subjectivity.

\section{RESULTS}

With GIS implementation of EPM through the SAGA GIS v.2.1 software, two most significant models are prepared: model of erosion (risk) coefficient Z; and model of mean annual sediment yield W. Both grid models are in $20 \mathrm{~m}$ resolution, corresponding to resolution of used input layers (datasets).

GIS-based model of the erosion coefficient $\mathrm{Z}$, shows values from 0 (deposition areas) to more than 3 (areas with excess erosion), with mean value of 0.4 (low to moderate erosion). However, there are large areas with high and very high erosion risk (values greater than 0.8). On these areas, even modest rainfall causes high production, transport and accumulation of eroded material. This is especially the case during heavy rains of more than $0.5 \mathrm{~mm} / \mathrm{min}$ and duration of more than $30 \mathrm{~min}$ [9]. 

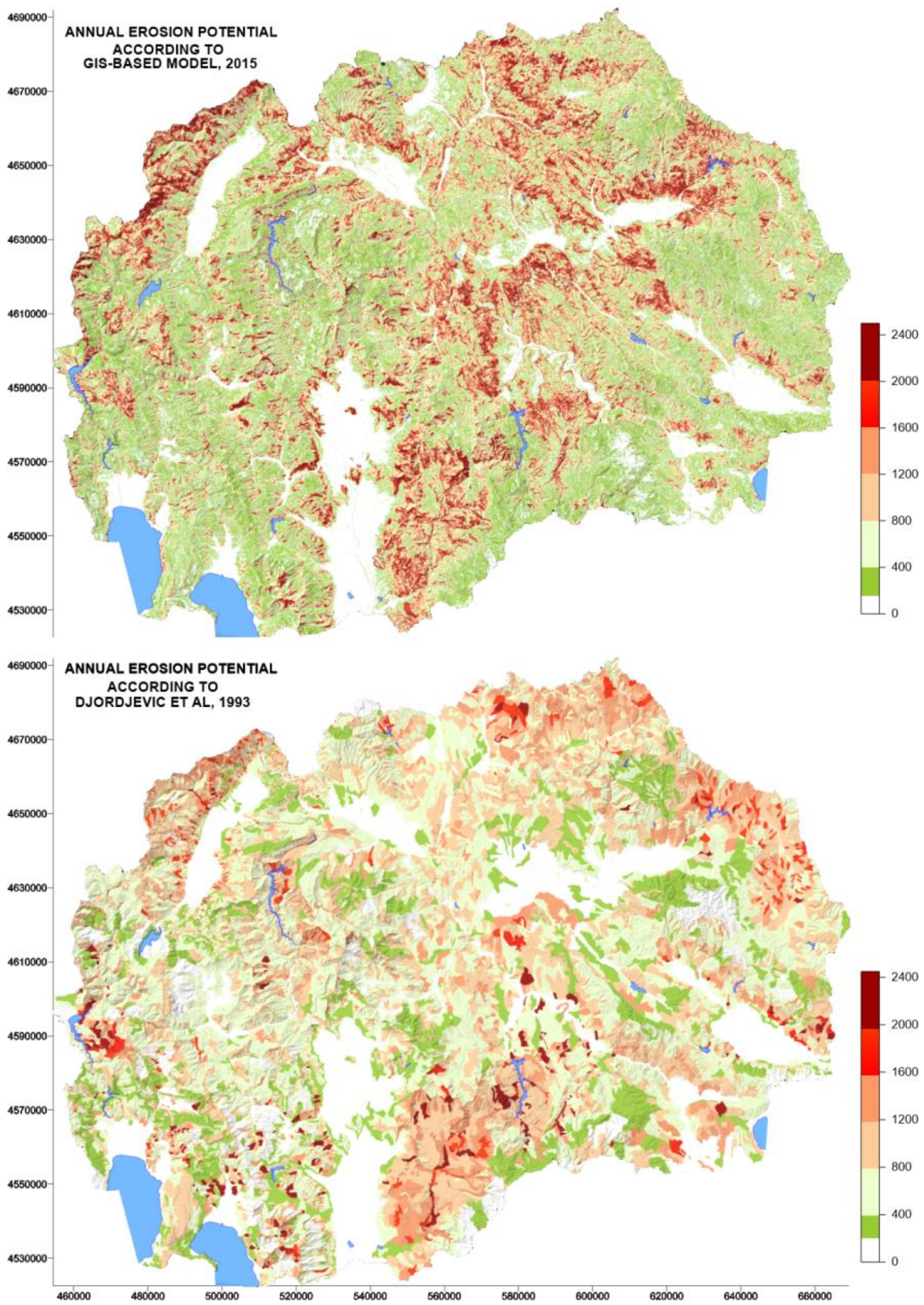

Figure 2. Maps of mean annual erosion production in the Republic of Macedonia according to the GISbased approach and traditional EPM-model (in $\left.\mathrm{m}^{3} / \mathrm{km}^{2} / \mathrm{y}^{-1}\right)$.

From the second output: GIS-based model of the sediment yield follows that average annual production of sediment yields in Macedonia is very high: $691 \mathrm{~m}^{3} / \mathrm{km}^{2}$ or 0.69 
$\mathrm{mm} / \mathrm{y}^{-1}$. Regardless of different approaches, this value coincide to that obtained in traditional Erosion map of the Republic of Macedonia [2], but the spatial structure of the erosion classes is apparently different (Fig. 2). However, there is a large spatial difference from the plains into depressions bottom to its step uncover sides and further toward the mountain hillslopes. In dense forest mountainous areas erosion rate is usually in range of $100-300 \mathrm{~m}^{3} / \mathrm{km}^{2} / \mathrm{y}^{-1}$, while some areas with high human impact have over $2000 \mathrm{~m}^{3} / \mathrm{km}^{2} / \mathrm{y}^{-}$ ${ }^{1}$. Highest erosion rate have areas in the Bregalnica catchment, the lower Crna catchment, the Pčinja catchment in the Tikveš Basin and many others. There actually appears severe or excessive erosion causing numerous destructive landforms, losing valuable fertile land and filling of river beds with a large amount of sediment material.

Table 1. Structure of areas according to the soil erosion classes with mean elevation for each class.

\begin{tabular}{|l|c|r|r|r|}
\hline Type & Int. $\mathbf{~ m}^{\mathbf{3}} / \mathbf{k m}^{\mathbf{2}} / \mathbf{y}$ & In $_{\mathbf{~ k m}} \mathbf{2}$ & \multicolumn{1}{|c|}{ In \% } & \multicolumn{1}{c|}{ Mean Elev. } \\
\hline Excess & $>2000$ & 1625.6 & 6.3 & 815.8 \\
\hline Severe & $1500-2000$ & 1351.7 & 5.3 & 815.6 \\
\hline Very High & $1000-1500$ & 2699.4 & 10.5 & 825.5 \\
\hline Medium-high & $750-1000$ & 2364.5 & 9.2 & 848.0 \\
\hline Medium & $500-750$ & 3807.5 & 14.8 & 881.5 \\
\hline Low & $250-500$ & 6048.4 & 23.5 & 931.0 \\
\hline Very low & $50-250$ & 7229.2 & 28.1 & 859.5 \\
\hline Deposition & $<50$ & 586.7 & 2.3 & 527.9 \\
\hline Total & & $\mathbf{2 5 7 1 3 . 0}$ & $\mathbf{1 0 0 . 0}$ & $\mathbf{8 2 9 . 2}$ \\
\hline
\end{tabular}

Because of more detailed analyses, erosion intensity is divided into 8 ranges (classes): from deposition, to excess erosion one. Spatial area and mean elevation for each class is calculated (Table 1). The results show dominance of areas with low to very low erosion rate with total of $51.6 \%$. They are related with forested mid-altitude mountain areas and plains in depressions which cause their higher mean elevation (Fig. 3-left). Deposition sites are connected with lakes, reservoirs and downstream valley parts of larger rivers, thus their low mean elevation in respect to other classes.
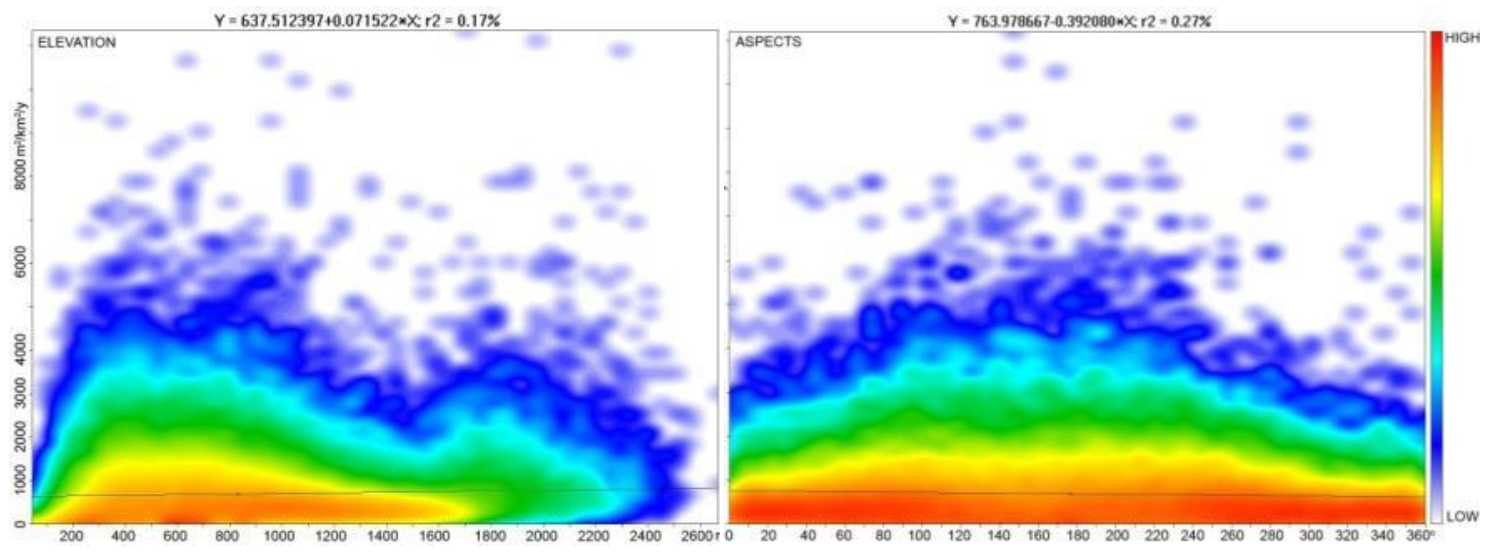

Figure 3. Graph of soil erosion intensity vs. elevation (left) and vs. slopes (right).

Table 2. Altitude vs. mean erosion rate (ER) in $\mathrm{m}^{3} / \mathrm{km}^{2} / \mathrm{y}^{-1}$, calculated from the GIS-model.

\begin{tabular}{|l|r|r|r|r|r|}
\hline Altitude & \multicolumn{1}{|c|}{ Area km $^{2}$} & Area in \% & Mean ER & Total ER & ER in \% \\
\hline $2000-2753$ & 354.0 & 1.4 & 1285.0 & 454890 & 2.6 \\
\hline $1500-2000$ & 1872.1 & 7.3 & 806.0 & 1,508913 & 8.5 \\
\hline $1000-1500$ & 5718.0 & 22.2 & 575.0 & 3,287850 & 18.5 \\
\hline $500-1000$ & 11297.3 & 43.9 & 712.2 & 8,045937 & 45.3 \\
\hline $250-500$ & 4875.0 & 19.0 & 780.6 & 3,805425 & 21.4 \\
\hline
\end{tabular}




\begin{tabular}{|l|r|r|r|r|r|}
$0-250$ & 1596.3 & 6.2 & 436.2 & 696306 & 3.9 \\
\hline Total/Avrg. & $\mathbf{2 5 7 1 2 . 7}$ & $\mathbf{1 0 0 . 0}$ & $\mathbf{6 9 0 . 9}$ & $\mathbf{1 7 , 7 6 4 9 0 4}$ & $\mathbf{1 0 0 . 0}$ \\
\hline
\end{tabular}

According to the model, significant percentages of the country cover areas with very high to severe and excess erosion rate with total of $22.1 \%$. They are mostly extended between depression bottoms and mid-altitude mountain slopes. For that reason, height range of these erosion classes is around 400-1000 m of altitude, and toward south-slope areas (Fig. 3-rigth) where human impact is the largest. Because of the high erosion rate, the landscape is often dissected into rills, gullies, badlands, earth pyramids etc. Here, instead of normal river catchments, torrential watersheds with high overload of sediments during the heavy rain occur.

\section{CONCLUSION}

In the Republic of Macedonia, large areas are under accelerated erosion caused by intensive human impact on suitable environment during centuries. Such areas are mostly steep, south inclined slopes of depressions and valleys, generally below $1000 \mathrm{~m}$ elevation, which were most appropriate for early settling as well. Because of accelerated erosion, the "original" landscape is very often dissected into rills, gullies, badlands, earth pyramids etc. Moreover, there are landscapes extremely devastated by soil erosion like the Bregalnica catchment, the lower Crna catchment, the Pčinja catchment and many others. On the other hand, lower parts of these catchments and valleys suffer severe deposition of eroded material with notable impact on fluvial processes. The lower sections of the Vardar, Pčinja, Bregalnica, and Crna River are bordered by large alluvial plains with fresh deposits, where lateral erosion, meandering and even channel accretion prevail. As a result of excessive deposition, many downstream riverbeds are now more than 10-15 m uplifted. Large tracts of agricultural land were abandoned with significant negative socialeconomic impacts on the rural environment.

Because of the high environmental and overall impact, accurate assessment of soil erosion intensity and identification of endangered areas is very significant issue [3]. In Macedonia, as well as in other countries in this region, estimation of average soil erosion potential and sediment yield is generally achieved with Erosion Potential Model (EPM) which show better results compared to other tested models as USLE [1]. However, determination of some significant factors in the model was subjective in nature since of visual estimation. Because of that, in implemented GIS approach, most of the parameters are derived from digital elevation model (DEM), satellite imagery and other digital datasets [9]. This approach has many advantages over traditional one:

- Preparing of input layers, calculations and final modelling is much faster than with traditional field-based approach, taking years to complete (Erosion map of Macedonia which is in use yet was prepared during the period of almost 20 years).

- Grid-based approach is far more spatially detailed (20 m resolution in our case) and usable than catchment based (Fig. 2).

- Entire GIS-based procedure is far less expensive, because almost all data layers (Landsat imagery, CLC model, digital elevation model etc.) as well as SAGA GIS software (or similar one) are free of charge.

- The subjectivity of individual expert estimations of visual erosion processes is drastically reduced and replaced with corresponding values from corresponding satellite imagery. 
- The ability of temporal monitoring with GIS-procedure, because it is easy to change some of input parameters (layers) with newer one, especially those based on frequently updated free satellite imagery (coefficient $\varphi$ or $\mathrm{X}^{*} \mathrm{a}$ ).

- Finally, original EPM model is limited in soil loss estimation during one season, month or one rain event. However, our detailed calculations show that it is possible even that with introduction of daily rain value instead of average annual precipitations $(\mathrm{H})$, in form of: $\mathrm{H}=(\mathrm{Hy} *(\mathrm{Hd} /(\mathrm{Hy} / 6)))$. Here $\mathrm{Hd}$ is daily value of rain and $\mathrm{Hy}$ is average yearly sum of precipitations in that area. This approach shows good observation field-fitting but it is not tested enough with field measurements which are necessary for evaluation. Even with that, usable rain-intensity scenarios can be produced showing erosion risk areas vs. daily rain amount/intensity.

However, there are several drawbacks and uncertainties of this approach which must be taken into account in further applications and developments.

- $\quad$ First of all is the problem with coefficient of rock and soil erodibility "Y". Values for this coefficient are relative and given by the author of the original model based generally on its estimations. This is rather problematic when numerous different types of rocks and soils must be considered. Also, it is very difficult to include and combine these two types of erodibility (rock and soil) in only one value, or to determine where the greater influences of each are. Because the Republic of Macedonia do not have high-detail soil properties map yet, only 100k digitalized geological map is used for now. Even that map is rather old, produced mostly in 1970-ties almost without updates afterward (despite that lithology is relatively "static" factor).

- The next is the problem with coefficient $X^{*}$ a referring to the land use type and pattern closely related to Corine Land Cover data. For the extent of Macedonia, the last available model is CLC2006 which is used in our procedure, but it is rather old and the newer CLC2012 is expected soon. Some events like large forest fires in 2007 and 2010 make significant changes in land cover which are not represented by CLC2006. Thus, alteration with newest satellite imagery is necessary to obtain real representation.

- Using the red spectral band from Landsat imagery as a basis for the coefficient of visible erosion processes $\varphi$, maybe is not the best choice in some cases. Namely, in this spectral band the white-colored resistant rocks like marbles and limestones correspond to high value or heavily eroded terrains which is not real. Thus, a better combination of spectral bands may provide more accurate values. Also, it is difficult to acquire the newest possible Landsat scenes of Macedonia (6 scenes of entire country) for the same season, with same quality and very low cloud cover.

\section{REFERENCES}

[1] Blinkov, I. and S. Kostadinov 2010. Applicability of various erosion risk assessment methods for engineering purposes, BALWOIS 2010 Conference Ohrid, Republic of Macedonia. 25 - 29 May 2010.

[2] Djordjevic M, Trendafilov A, Jelic D, Georgievski S, A. Popovski 1993. Erosion map of the Republic of Macedonia. Memoir. Water Development Institute, Skopje. 89 p. (in Macedonian) 
[3] Dragicević S., D. Filipović, S. Kostadinov, R. Ristić, I. Novković, N. Zivković, G. Andjelković, B. Abolmasov, V. Secerov, S. Djurdjić. Natural hazard Assessment for Land-use Planning in Serbia. Int J Environ Res., 5(2), 2011a, pp. 371-380.

[4] Eckelmann, W., Baritz, R., Bialousz, S., Bielek, P., Carré, F., Houšková, B., Jones, R.J.A., Kibblewhite, M.G., Kozak, J., Le Bas, C., Tóth, G., Tóth, T., Várallyay, G., Yli Halla, M., \& Zupan, M. (2006). Common Criteria for Risk Area Identification according to Soil Threats. EUR 22185 EN. Luxembourg: Office for Official Publications of the European Communities.

[5] Gavrilović, S. 1972. Engineering of Torrents and Erosion, Journal of Construction (Special Issue), Belgrade, Yugoslavia. (in Serbian)

[6] Globevnik L., Holjevic D., Petkovsek G. \& Rubinic J. (2003). Applicability of the Gavrilovic method in erosion calculation using spatial data manipulation. Erosion Prediction in Ungauged Basins: Integrating Methods and Techniques (Proceedings of symposium HS01 held during IUGG2003 at Sapporo, July 2003). IAHS Publ. No. 279, 224-233.

[7] Grimm, M. R. Jones, L. Montanarella 2001. Soil Erosion Risk in Europe. European Soil Bureau Institute for Environment \& Sustainability JRC Ispra, pp. 1-40

[8] Milevski I. (2001). Modeling of soil erosion intensity with software tools, in the example of Kumanovo Basin. Proceedings of II Congress of Macedonian Geographic Society, Ohrid, 49-57. (in Macedonian)

[9] Milevski I. 2011. Factors, Forms, Assessment and Human Impact on Excess Erosion and Deposition in Upper Bregalnica Watershed (Republic of Macedonia). In: Human Impact on Landscape, Ed. S. Harnischmachter and D. Loczy. Zeitschrift für Geomorphologie, Vol. 55, Suplementary issue 1, Stuttgart, 77-94.

[10] Milevski I. 2015. Digital Model of the Mean Annual Temperature and Precipitation of the Republic of Macedonia. Geographical Reviews No. 48, Skopje. pp. 33-38.

[11] Milevski I., Dragicevic S., A. Georgievska 2013. GIS and RS-based modelling of potential natural hazard areas in Pehchevo municipality, Republic of Macedonia. Journal of the Geographical Institute „Jovan Cvijić” SASA, 63(3): 95-107. 